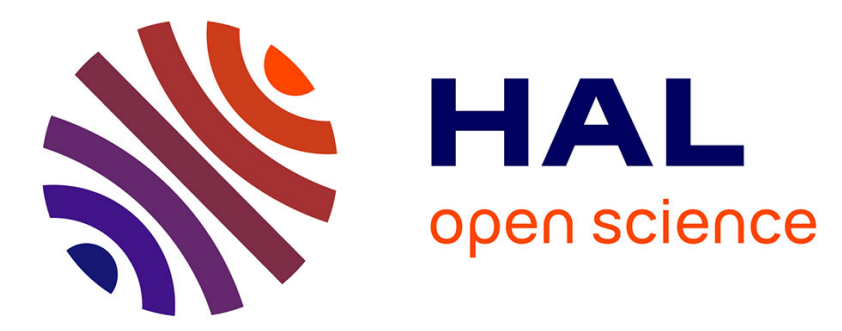

\title{
Fractal surface of amorphous platinum pyrimidine complexes in solid state as revealed by anomalous small angle scattering
}

\author{
R. Serimaa, T. Laitalainen, M. Regan, A. Bienenstock
}

\section{- To cite this version:}

R. Serimaa, T. Laitalainen, M. Regan, A. Bienenstock. Fractal surface of amorphous platinum pyrimidine complexes in solid state as revealed by anomalous small angle scattering. Journal de Physique IV Proceedings, 1993, 03 (C8), pp.C8-361-C8-364. 10.1051/jp4:1993874 • jpa-00252305

\section{HAL Id: jpa-00252305 https://hal.science/jpa-00252305}

Submitted on 1 Jan 1993

HAL is a multi-disciplinary open access archive for the deposit and dissemination of scientific research documents, whether they are published or not. The documents may come from teaching and research institutions in France or abroad, or from public or private research centers.
L'archive ouverte pluridisciplinaire HAL, est destinée au dépôt et à la diffusion de documents scientifiques de niveau recherche, publiés ou non, émanant des établissements d'enseignement et de recherche français ou étrangers, des laboratoires publics ou privés. 


\title{
Fractal surface of amorphous platinum pyrimidine complexes in solid state as revealed by anomalous small angle scattering
}

\author{
R. SERIMAA, T. LAITALAINEN*, M.J. REGAN ${ }^{* *}$ and A. BIENENSTOCK ${ }^{* *}$ \\ Department of Physics, P.O. Box 9, University of Helsinki, 00014 Helsinki, Finland \\ * Department of Chemistry, P.O. Box 6, University of Helsinki, 00014 Helsinki, Finland \\ ** Stanford Synchrotron Radiation Laboratory, Bin 69, Stanford, P.O. Box 4349, CA 94305, U.S.A.
}

\begin{abstract}
The amorphous platinum greens, which were synthesized from $\mathrm{Pt}\left(\mathrm{NH}_{3}\right)_{2}\left(\mathrm{H}_{2} \mathrm{O}\right)_{2}\left(\mathrm{NO}_{3}\right)_{2}$ or from $\mathrm{Pt}\left(\mathrm{NH}_{3}\right)_{2}\left(\mathrm{H}_{2} \mathrm{O}\right)_{2}\left(\mathrm{SO}_{4}\right)$ and uridine, 5 -bromouridine and ftorafur, were studied in the solid state by anomalous small angle x-ray scattering. The intensity curves exhibit a power-law dependence, which is likely to originate from large aggregates that are quite compact yet have rough surfaces. The surface fractal dimension varied between 2.2-2.7. The radius of gyration of the particles in the aqueous reaction mixture before precipitation was only about $5 \AA$. Thus it was concluded that the aggregates barely nucleate during the reaction and grow during the precipitation with acetone.
\end{abstract}

\section{Introduction}

Amorphous, mixed-valent platinum pyrimidine complexes are known for their intense color and antitumor activity.[1,2,3,4] From our anomalous wide angle x-ray scattering (AWAXS) studies[5] of several Pt-greens in the solid state, tetranuclear Pt-complexes dominate the scattering in most cases. We found only one product, Pt-5-bromouridine green, with a dinuclear major Pt-complex. From earlier small-angle $x$-ray scattering (SAXS) studies, $[6]$ the same products dissolved in water into dimers, which may then aggregate. At a concentration of $14 \mathrm{mg} / \mathrm{ml}$ the radii of gyration varied between 4-7 $\AA$. We report here a complementary study of $\mathrm{Pt}$-complex aggregation in the solid state by using anomalous small-angle $x$-ray scattering (ASAXS) which provides insight on a length scale from 5-500 $\AA$ as well as $\mathrm{Pt}$-specific information. We studied also the aqueous reaction mixture before the precipitation and solidification of the product by SAXS. Our study of Pt-complex aggregation defines new structural characteristics that may play an important role in understanding and controlling the complexes' properties.

\section{Experimental}

The solid products chosen for the ASAXS study are the following: Pt-uridine green nitrate (1), Pt-uridine green sulfate (2), Pt-uridine violet sulfate (3), Pt-5-bromouridine green sulfate (4), and $\mathrm{Pt}$-ftorafur green sulfate (5). The main differences of the syntheses are as follows. The Pt-green (1) was synthesized from $\mathrm{Pt}\left(\mathrm{NH}_{3}\right)_{2}\left(\mathrm{H}_{2} \mathrm{O}\right)_{2}\left(\mathrm{NO}_{3}\right)_{2}$ and (2-5) from $\mathrm{Pt}\left(\mathrm{NH}_{3}\right)_{2}\left(\mathrm{H}_{2} \mathrm{O}\right)_{2}\left(\mathrm{SO}_{4}\right) \cdot[3,6] \mathrm{Pt}$-greens $(1,2,4,5)$ were synthesized by hydrogen peroxide oxidation in $70^{\circ} \mathrm{C}$ for $0.5-1 \mathrm{~h}$ and $\mathrm{Pt}$-violet (3) was synthesized without an oxidant in room temperature for $170 \mathrm{~h}$. The solid products were precipitated from the (gel filtered) aqueous reaction mixture by addition of acetone and dried. For comparison, the reaction mixture of Pt-green (2) was measured before precipitation by SAXS. 
The solid samples were measured at the eight-pole focused wiggler end-station 4-2 of the Stanford Synchrotron Radiation Laboratory (SSRL) with the SAXS camera[7] of the Biotechnology group. The basic line consists of a bent cylindrical mirror and a Si(111) double-crystal monochromator. All the products (1-5) were measured at $8 \mathrm{keV}$ and Pt-greens $(2,4)$ below the Pt $\mathrm{L}_{\mathrm{II}}$ edge $(11.1,11.2$, $11.3,11.4$, and $11.5 \mathrm{keV}$ ). The absence of fluorescence from $\mathrm{Pt}$ at $8 \mathrm{keV}$ was used to determine the background due to near-edge contributions of fluorescent processes at $11.1-11.5 \mathrm{keV}$.

The incident beam was defined by two sets of slits (each $0.25 \mathrm{~mm}$ vertical by $0.50 \mathrm{~mm}$ horizontal) separated by an evacuated chamber roughly one meter in length. The samples were held in transmission and separated by an evacuated chamber about $2.7 \mathrm{~m}$ from a linear position-sensitive proportional counter. The thicknesses of the samples were between $0.2-0.4 \mathrm{~mm}$. Miniature ionization chambers, placed directly before and after the sample, were used to normalize scattering data. The data were corrected for absorption and any nonlinearities in the detector, scaled to the primary beam intensity, and background subtracted. The range of reciprocal space covered is from $k=0.006$ to $0.28 \AA^{-1}\left(k=\frac{4 \pi}{\lambda} \sin \theta\right.$, where $\lambda$ is the wavelength and $2 \theta$ the scattering angle). Smearing effects due to finite beam size were considered but are negligible due to the small spot size used.

The reaction mixture was measured with $\mathrm{Cu} K_{\alpha}$ radiation monochromatized by means of a total reflecting mirror (Huber small-angle chamber 701) and Ni-filter. The scattered radiation was detected by a linear one-dimensional position sensitive proportional counter (MBraun OED-50M). A narrow slit $(1 \mathrm{~mm})$ was installed in front of the detector window. The primary beam is narrow (FWHM $\leq 0.008 \AA^{-1}$ ) compared to its length $\left(F W H M \approx 0.16 \AA^{-1}\right.$ ). The reliable range of measurements was from $k=0.04$ to $0.70 \AA^{-1}$. The sample container was a narrow $(0.8 \mathrm{~mm})$ cavity in a steel frame with thin stretched polypropylene foils as flat faces $(6 \mu \mathrm{m})$. The background due to the solvent and the foils was subtracted and the intensity curve was corrected for beam-length smearing.[9]

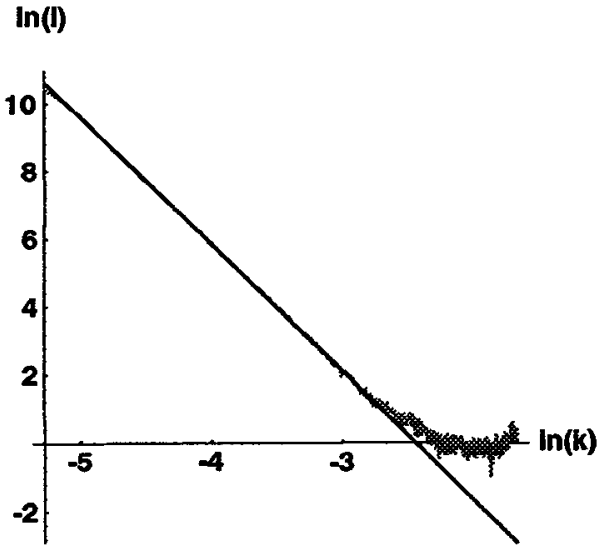

Figure 1. The power law fit for Pt-green (2)

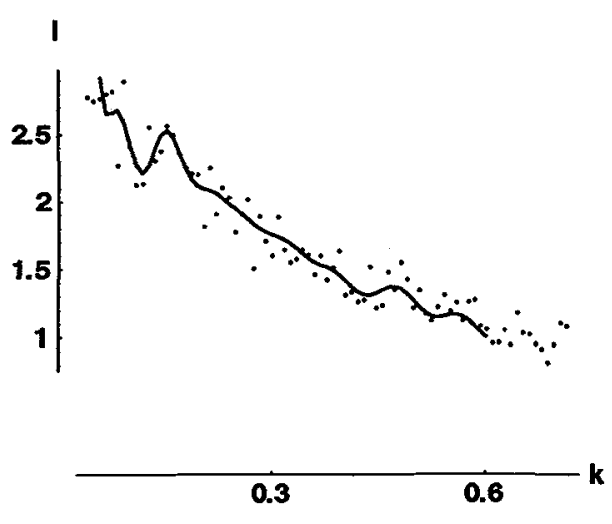

Figure 2. The intensity (arbitrary units) of the reaction mixture (2) (dots) and the model (solid line) as a function of $k\left(\AA^{-1}\right)$

\section{Results}

The samples scatter strongly in the small-angle range and the intensity curves show a power-law dependence. An asymptotic power law $I(k) \propto k^{-\alpha}$ was fit to the experimental intensity curve to determine $\alpha$. This technique was chosen instead of fitting a line to pairs of points $(\ln (k), \ln (I))$, because the variances of $I$, which are needed for the proper normalization of the minimization function, are readily available. The fitting results are shown in Table 1, and Figure 1 presents the power law fit for Pt-green (2). The slope $\alpha$ is between 3.35-3.76, which indicates that the scattering units are surface fractals.[10] The surface fractal dimension $D_{s}=6-\alpha$ varied between 2.2 and 2.7. 
A power law distribution of uniform pores would also give similar slopes, but since the products are amorphous, it seems unlikely that the pores would be uniform.

The data extended far enough in $k$ to exhibit the same first 'large angle scattering maximum' that was observed in the AWAXS work. This maximum exists in the intensity curves of (1-3), and is especially pronounced for Pt-violet (3) and is at lowest $k$ for Pt-green (1). The intensity curves were in reasonable agreement with Guinier's law for the short range of $k=0.006$ to $0.008 \AA^{-1}$, only 5-7 data points. The radii of gyration $\left(R_{g}\right)$ varied between 310 and $370 \AA$. It is concluded that the smallest reliable $k$ is too large to obtain a full picture of the structure of the samples.

The anomalous effect was detected at the $\mathrm{Pt} \mathrm{L}_{\mathrm{III}}$-edge, which excludes the possibility that $\mathrm{Pt}$ is uniformly distributed in the sample. The differences of two intensity curves at two energies are largest at $k\left(0.03 \AA^{-1}\right.$. A reasonable model is one that accounts for the small angle scattering from aggregates of $\mathrm{Pt}$-complexes. The $\mathrm{Pt}$-complex was approximated as a two-component system of $\mathrm{Pt}$ 's $(a)$ and other atoms $\mathrm{C}, \mathrm{N}, \mathrm{O}, \mathrm{S}$, and $\mathrm{H}(b)$. To verify this model, the behaviour of the calculated and the experimental invariants, $Q=\int_{0}^{\infty} I(k) k^{2} d k$, as a function of energy are compared. The invariant $Q$ of a system of Pt-complexes (and voids) then behaves according to $Q \propto\left(x_{a} f_{a}+x_{b} f_{b}\right)^{2}$, where $x_{a}$ and $x_{b}$ are the atomic fractions, and $f_{a}$ and $f_{b}$ the scattering factors of the components $a$ and $b$.

To calculate the invariants, a constant background from near-edge effects must be subtracted. The scans were fit to $A k^{-\alpha}+B$, where $A$ and $B$ are fitting parameters and $\alpha$ the same as at $8 \mathrm{keV}$. The integral from 0 to the smallest $k$ was estimated with a triangular approximation, and the integral from the largest $k$ to $\infty$ was determined assuming that the intensity obeys the power law. This latter contribution is $9 \%$ of the total invariant.[8] The anomalous effect is not large: the relative change in the experimental invariant at $11.1-11.5 \mathrm{keV}$ is about $3 \%$ for both Pt-greens $(2,4)$. The deviations of the experimental scaled invariants $Q(E) / Q(11.1 \mathrm{keV})$ from the calculated ones are 1 and $2 \%$ for (2) and (4), respectively.

Table 1. Power law fit to the intensity curves measured at $8 \mathrm{keV}$. The exponent is denoted by $\alpha$ and the surface fractal dimension by $D_{s}=6-\alpha$. The power law was obeyed from $k=k_{\min }$ to $k_{\max }$. The goodness of fit was defined as $\chi^{2}=\frac{1}{N} \sum_{i=1, \ldots, N}\left(I^{\exp }\left(k_{i}\right)-I^{\text {calc }}\left(k_{i}\right)\right)^{2} / I^{\exp }\left(k_{i}\right)$, where $N$ is the number of points in the fitting regime.

$\begin{array}{lllllll}\text { Sample } & & D_{s} & \alpha & k_{\min } & k_{\max } & \chi \\ \text { Pt-uridine green } & (1) & 2.5 & 3.52 & .010 & 0.06 & 0.7 \\ \text { Pt-uridine green } & (2) & 2.2 & 3.76 & .007 & 0.07 & 0.6 \\ \text { Pt-uridine violet } & (3) & 2.7 & 3.35 & .007 & 0.05 & 0.5 \\ \text { Pt-5-bromouridine green } & (4) & 2.4 & 3.65 & .008 & 0.06 & 0.7 \\ \text { Pt-ftorafur green } & (5) & 2.3 & 3.71 & .007 & 0.04 & 0.8\end{array}$

The intensity curve of the reaction mixture of (2) obeyed Guiner's law with the $R_{g}$ of about 5 $\AA$ at $k=0.04$ to $0.15 \AA^{-1}$. The $R_{g}$ is equal to that of a tetranuclear Pt-chain.[6] To estimate the amount of tetranuclear units in the mixture, 8-12 dinuclear Pt-units were placed at random in a simulation cell and, with a random diffusion process, fit to the experimental intensity curve.[6] In the refinement the simulated annealing technique was used. The agreement with data is good (Fig. 2). According to the simulations discrete dinuclear Pt-units dominate the scattering with the share of tetranuclear Pt-chains about $25 \%$.

\section{Discussion}

All the products (1-5) contain large aggregates, which are quite compact yet have a rough surface. The aggregates are much larger in the solid state than in solution, which implies that, when mixed with water, they decompose. Pt-violet (3) exhibits the roughest surface. It also has the most prominent large angle maximum and might be slightly more ordered than Pt-green (2). Changing the counter ion from sulfate to nitrate might increase the surface roughness, since $D_{s}$ of Pt-green 
(1) was larger than $D_{s}$ of (2). It also affects the structure since the positions of 'the wide angle maximum' differs. However, our results are inconclusive at this point since a WAXS study of (1) has not been performed, and hence we cannot identify Pt-greens (1) and (2) as having the same primary Pt-units.

Pt-gren (4) shows slightly increased surface irregularity compared to (2). The AWAXS results indicate that (4) consists of dinuclear Pt-units, and that the shortest distance between two dinuclear units is larger than in the tetranuclear chains of (2). Both biologically active Pt-greens $(2,5)$ show a relatively low degree of surface irregularity with about the same $D_{s}$. However, the range of $k$, where the power law is obeyed, is shorter for (5). The absence of the three OH-groups in the ligand seems to have little effect on the surface roughness of the aggregates. This may indicate that intermolecular hydrogen bonding is not the primary reason for the aggregate formation.

The results for the reaction mixture indicate that only small aggregates are formed during the reaction itself. The fractal aggregates are thus formed during the precipitation and drying. The addition of acetone might cause formation of a colloidal system. The model of irreversible aggregation[11] explains the appearance of surface fractality in colloids. The surface fractal dimension from the simulations is 2.52 ,[11] which agrees well with our results for products (1) and (3). The small aggregates in dilute water solutions may form by a different mechanism, however.

\section{Acknowledgement}

The financial support of The Academy of Finland, The University of Helsinki and Technology Development Centre is gratefully acknowledged. Support for MJR and AB was provided by the US Department of Energy (DOE), Office of Basic Energy Sciences. Part of this work was done at SSRL, which is supported by the DOE, Division of Chemical Sciences and the NIH, Biotechnology Resource Program, Division of Research Resources.

\section{References}

[1] DAVIDSON, J. P., FABER, P. J., FISCHER, R. G., MANSY, S., PERESIE, H. J., ROSENBERG, B. and VanCAMP, L. Cancer Chemother. Rep., Part 1, 59 (1975) 287.

[2] FARRELL, N. Transition metal complexes as drugs and chemotherapeutic agents. 1989. Kluwer Academic Publishers, The Netherlands.

[3] SHIMURA, T., TOMOHIRO, T., LAITALAINEN, T., MORIYAMA, H., UEMURA, T. and OKUNO, Y., Chem. Pharm. Bull. 36 (1988) 448.

[4] OKADA, T., SHIMURA, T. and OKUNJ, H. Chem Pharm. Bull. 40 (1992) 264.

[5] SERIMAA, R., LAITALAINEN, T., VAHVASELKÄ, S., PAAKKARI, T. and BIENENSTOCK, A. SSRL Annual Report 1992.

[6] SERIMAA, R., LAITALAINEN, T. and VAHVASELKÄ, S. To be published.

[7] WAKATSUKI, S., HODGSON, K.O., ELIEZER, D., RICE, M., HUBBARD, S., GILLIS, N., DONIACH, S., SPANN, U. Rev. Sci. Instrum. 63 (1992) (2), 1736.

[8] SERIMAA, R., LAITALAINEN, T., REGAN, M. and BIENENSTOCK, A. SSRL Annual Report 1992.

[9] LAKE, J. Acta Cryst. 23 (1967) 191.

[10] SCHMIDT, P. W. J. Appl. Cryst. 24 (1991) 414.

[11] KOLB, M. and HERRMANN, H. J. Phys. Rev. Lett. 59 (1987) 454. 